\title{
A conjoint experiment of how design features affect evaluations of participatory platforms
}

\author{
Henrik Serup Christensen \\ Department of Political Science \\ Åbo Akademi University \\ Henrik.christensen@abo.fi
}

Date: 5 November 2019

The published version (with slight changes) appears in Government Information Quarterly: Dol: https://authors.elsevier.com/a/1covt,Grm0GDrA

\begin{abstract}
:
Online participatory platforms are introduced to boost citizen involvement in political decision-making. However, the design features of these platforms vary considerably, and these are likely to affect how prospective users evaluate the usefulness of these platforms. Previous studies explored how prevalent different design features are and how they affect the success of platforms in terms of impact, but the attitudes of prospective users remain unclear. Since these evaluations affect the prospects for launching successful participatory platforms, it is imperative to assess what citizens want from such digital possibilities for participation. This study uses a conjoint experiment $(\mathrm{n}=1048)$ conducted in Finland that explore the impact of seven design features: Discussion possibilities; Interaction with politicians and experts; Information availability, Aim of participation; Identity verification; Anonymous participation and Accessibility. Furthermore, it is examined whether the effects differ across use of ICTs measured by generation, time online and prior use of participatory platforms. The results suggest that most design features have clear effects on evaluations, and that deliberative features have the strongest effects. Furthermore, the effects are relatively stable across prior use although the less experienced put a stronger emphasis on verification.
\end{abstract}

Key words: e-democracy; participatory platforms; online deliberation; design features; conjoint analysis 


\section{Introduction}

Early proponents of "teledemocracy" envisioned that information and communication technologies (ICTs) could facilitate democratic participation (Dutton, 1992). Eminent political scientist Robert Dahl also quickly imagined that technological advances could transform democracy by creating virtual agoras where citizens could take part in political decision-making (Dahl, 1989). Although such visions today appear to have exaggerated the transformative power of ICTs, many still argue that these will play a prominent role in adapting democracy to confront current and future challenges (Coleman \& Shane, 2012; Neblo et al., 2018).

Online participatory platforms is one way ICTs allow citizens to provide input into political decisionmaking (Esau et al., 2017). Such platforms exist at different levels of government all over the world, but their aims and scope vary considerably (United Nations, 2018). Consequently, a great deal of scholarship is devoted to exploring aims and consequences of such participatory platforms (Åström \& Grönlund, 2012; Esau et al., 2017; Kitsing, 2011; Manoharan \& Holzer, 2012; Panopoulou et al., 2018; Tambouris \& Gorilas, 2003).

Several of these studies explicitly examine failures (Anthopoulos et al., 2016; Choi \& Chandler, 2020; Elkadi, 2013; Toots, 2019), which clearly suggests that these platforms frequently fail to meet the expectations. One reason may be that the perspective of citizens is frequently neglected when designing new platforms. It is difficult to ask prospective users directly since they often do not have clear ideas of what they want, which leads to unreliable answers (Zaller, 1992). Research on website design therefore frequently eschew user evaluations and instead rely on measures such as eye tracking of usage to evaluate design features (Nielsen \& Pernice, 2010). While such studies can give important insights into the technical functioning of platforms, they do not make it possible to establish how different design features affect how citizens evaluate the usefulness of participatory platforms, which is arguably the more important question from a democratic perspective. To activate citizens and make them take advantage of the possibilities on offer, it is important that the platforms offer the functions that citizens demand, as is the case with any participatory process (Christensen, 2020). 
Previous studies have examined the impact of particular features such as identity verification on participation and behavior on participatory platforms (Esau et al., 2017; Moore et al., 2020). Nevertheless, there is no comprehensive empirical study that examines how the incorporation of design features affects citizens' evaluations of prospective platforms. This study therefore investigates this with a conjoint experiment that makes it possible to examine the impact of several features simultaneously without asking people directly about their preferences.

\section{Background}

In this section, I first define what the central concepts participatory platform and design feature entail in this study. Following this, I outline three democratic ideals and explain how these ideals shape what functions participatory platforms offer prospective users. I then explain why the possibilities offered by participatory platforms must correspond to what prospective users demand in order to succeed in mobilizing them. Finally, I clarify that it is necessary to consider differences in demands between groups in society to avoid inequalities in participation.

The advent of participatory platforms illustrates the impact ICTs have had on democratic practices. Participatory platform here refers to online websites or apps provided by authorities to give users the chance to provide input into political decision-making. That they are launched by government authorities entails that they have an official status and form part of the formal political system. This distinguishes them from grassroot websites that also aim to mobilize citizens, but without the authoritative clout that the participatory platforms under scrutiny here possess.

That these platforms are directly linked to formal political system allow users to provide input into the political decision-making. This distinguishes them from governmental websites that only provide official information, and, more importantly, from service platforms where users interact with authorities in a capacity of being service receiver or client, rather than in a capacity of being citizen (Anttiroiko et al., 2014). A distinction can here be drawn between e-government and e-democracy, where the former concerns the use of online public services (Choi \& Chandler, 2020; Holden et al., 
2003; Lim, 2010), while the latter refers to online efforts to involve citizens in political decision-making (Chadwick, 2003; Christensen, 2013; Päivärinta \& Sæbø, 2006). Although both are important, the individual in a citizen role is of primary importance from a democratic perspective (Chadwick, 2003).

All participatory platforms consist of a bundle of design features, which is here used to denote possibilities and demands offered to users on a given platform (Åström \& Grönlund, 2012; Esau et al., 2017; Fung, 2003; Steibel \& Estevez, 2015). Examples of such design features include whether a platform allows users to discuss a topic with other users, or whether it is possible to ask questions from decision-makers. It can be difficult to decide exactly what design features to include since it involves a trade-off between empowerment and usability. A platform should incorporate the necessary features that empower users to perform the tasks they wish to accomplish. However, jamming the platform with too many features diminish usability by making it difficult to comprehend what possibilities exist and how to use them. A participatory platform therefore needs to strike a balance between including features demanded by most citizens while disregarding unnecessary design features that few will take advantage of (Panopoulou et al., 2018).

At the same time, what design features are included reveals what democratic ideal the platform adheres to. This is important since there are important differences in the democratic ideals of citizens and these influence their patterns of political participation (Bengtsson \& Christensen, 2016). It is therefore imperative to ensure a correspondence between the ideals embodied in the platforms and the ideals of citizens to ensure digital mobilization. It is helpful to distinguish three democratic ideals that differ in their conceptualizations of the role of citizens in democracy (Christensen, 2013; Held, 2006; Päivärinta \& Sæbø, 2006): The representative, the participatory and the deliberative democratic ideal.

According to the representative ideal, democracy is about citizens being able to select their leaders in free and fair elections. Accordingly, participatory platforms should help citizens keep track of their official representatives and thereby enable them to punish or reward them in regular elections. Hence, 
it becomes imperative to provide information on decision-making processes and the actions of representatives, but not necessarily to allow citizens to take an active role in the decision making. The participatory democratic ideal advocates a more active role for citizens as this helps ensure that their views are given due consideration during the decision-making (Pateman, 1970). Hence, participatory platforms that subscribe to this ideal should turn the information flow and allow citizens to provide input into the decision-making, for example by making it possible for users to ask questions, make recommendations, and even take final decisions to ensure that decisions correspond to the preferences of citizens (Chadwick, 2003). The deliberative democratic ideal also emphasizes citizen involvement, but to a larger extent than the two other ideals highlights the importance of developing and modifying preferences during participation to reach an enlightened understanding of the issues involved (Chambers, 2003; Fishkin, 2009). Compared to the unidirectional flows of information in the representative and participatory ideals, communication is here multidirectional and interactive (Chadwick, 2003: 449). Accordingly, participatory platforms should emphasize deliberation among citizens, possibly also including their representatives, to achieve a dialogue based on respect and mutual consideration between participants (Coleman \& Shane, 2012; Dahlberg, 2001; Dahlgren, 2005). An important question that follows from this is who will take advantage of the possibilities on offer? The possibilities offered by participatory platforms should ideally be equally accessible to all citizens. However, demands for specific features may vary systematically across subgroups. Were this to be the case, including them can empower certain groups while excluding others, thereby creating a digital divide that exacerbate existing differences in participation (Norris, 2001; Panopoulou et al., 2018).

For the present purposes, it is particularly important to determine whether people who are accustomed to using ICTs have entirely different preferences for the design of participatory platforms. Those who already use ICTs are likely to differ from the general population in key socio-demographic characteristics such as age, education and place of living (Dijk, 2005; DiMaggio \& Garip, 2012; Warschauer, 2004). Because of their familiarity with ICTs, they are also likely to hold different ideas 
about what design features a participatory platform should incorporate. Constructing a new platform solely on the demands of experienced users may lead to insurmountable obstacles for less experienced users to take full advantage of the participatory platforms. Consequently, these may unwillingly create deeper digital divides rather than help even out existing differences. On the other hand, this risk would be negligible when people have similar evaluations across prior usage. It is therefore important to examine this aspect to understand how the inclusion of different design features affect the impact of participatory platforms on democratic inclusiveness.

\section{Research design}

The study considers two broad hypotheses ${ }^{1}$ :

H1: Design features influence evaluations of participatory platforms.

H2: The effects of design features differ across prior use of ICTs.

\subsection{A conjoint experiment of how design features influence evaluations of participatory platforms}

A choice-based conjoint experiment is used to examine the causal impact of seven central design features on evaluations of participatory platforms. Conjoint analysis, which was developed in marketing during the 1970s, offers a tool for examining causal effects of several treatment components simultaneously through relatively simple statistical analyses without unnecessary assumptions (Hainmueller et al., 2014).

In the choice-based version used here, respondents are presented with descriptions of two or more profiles that are created by randomly varying multiple attributes with several levels ((Hainmueller et al., 2014). These attribute levels should be discrete categories describing theoretically relevant values of the attribute in question.

\footnotetext{
${ }^{1}$ No preregistration was made for this study. I do not present specific hypotheses for each of the design features since no clear expectations for the effects of each were established beforehand.
} 
The profiles are in this study descriptions of hypothetical participatory platforms that are described with the help of design features (the attributes), as described in Table 1. Hence, respondents base their evaluations on descriptions key design features of each participatory platform rather than actual experiences with them. An illustration translated into English of how the conjoint analysis was presented to respondents in Qualtrics is shown in Appendix B.

When comparing the descriptions of the two participatory platforms, respondents were asked to select the one they would prefer to see introduced by the Finnish government. Each respondent made six such comparisons. Although Bansak et al. (2018) demonstrate that treatment effects remain stable even with a larger number of comparisons, the number of comparisons was limited to six to avoid any risk of response fatigue.

Conjoint analysis is valuable for the present research purposes since it is possible to discern how design features affect respondents' evaluations of participatory platforms. The respondents do not need to understand the technical details of what a specific design feature entails since the emphasis is on examining how the inclusion of a feature affects the spontaneous evaluation of the introduction of a participatory platform. While such evaluations do not say much about whether a platform would be useful, they do affect whether the public will welcome the introduction and therefore also the likelihood of successfully engaging the public. Furthermore, it is possible to explore differences across prior ICT use to discern whether the effects are homogenous across the population (Abramson et al., 2019; Leeper et al., 2020).

Table 1 shows the design features and the possible values included in the conjoint. 
Table 1. Design features and values

\begin{tabular}{|c|c|c|}
\hline Design & Description & Value ( $R=$ reference category) \\
\hline Discussions & $\begin{array}{l}\text { Possibilities for } \\
\text { discussions among } \\
\text { participants }\end{array}$ & $\begin{array}{l}\text { 1. No discussions (R) } \\
\text { 2. Unmoderated discussions between participants } \\
\text { 3. Discussions between participants supervised by a neutral moderator }\end{array}$ \\
\hline Interaction & $\begin{array}{l}\text { Possibilities for } \\
\text { interaction with } \\
\text { politicians and } \\
\text { experts }\end{array}$ & $\begin{array}{l}\text { 1. No interaction }(\mathrm{R}) \\
\text { 2. Submit questions to experts and politicians that are answered after a few days } \\
\text { 3. Chat questions to experts and politicians that are answered immediately } \\
\text { 4. Ask questions to experts and politicians in occasional live meetings with } \\
\text { webcams }\end{array}$ \\
\hline Information & $\begin{array}{l}\text { Availability of } \\
\text { information }\end{array}$ & $\begin{array}{l}\text { 1. No information is available }(R) \\
\text { 2. Access to all official documents in connection to decisions } \\
\text { 3. Short overview of important issues in connection to decisions }\end{array}$ \\
\hline $\begin{array}{l}\text { Decision- } \\
\text { making role }\end{array}$ & $\begin{array}{l}\text { The main goal of } \\
\text { participation }\end{array}$ & $\begin{array}{l}\text { 1. Undefined }(\mathrm{R}) \\
\text { 2. Come up with new suggestions and ideas } \\
\text { 3. Discuss existing suggestions and ideas } \\
\text { 4. Decide on final policies }\end{array}$ \\
\hline Verification & $\begin{array}{l}\text { Verification of the } \\
\text { identifies of } \\
\text { participants }\end{array}$ & $\begin{array}{l}\text { 1. No verification }(R) \\
\text { 2. Weak verification by sending email link } \\
\text { 3. Strong verification with bank codes or personal id }\end{array}$ \\
\hline Anonymity & $\begin{array}{l}\text { Possibility to } \\
\text { participate } \\
\text { anonymously }\end{array}$ & $\begin{array}{l}\text { 1. Not possible }(\mathrm{R}) \\
\text { 2. Possible }\end{array}$ \\
\hline Accessibility & $\begin{array}{l}\text { Possibilities for } \\
\text { accessing platform }\end{array}$ & $\begin{array}{l}\text { 1. Via Internet browser on computer }(\mathrm{R}) \\
\text { 2. In an application for phones and tablets }\end{array}$ \\
\hline
\end{tabular}

In the following, I outline the reasons for including these design features based on previous literature.

None of the studies surveyed aimed to examine the impact of design features on evaluations in a comparable manner to the present one. Instead, they focused on specific aspects and their likely consequences for issues such as participation, behavior and satisfaction in an online setting. While these contributions do not always empirically test their propositions, they help to establish the likely impact of the design features on evaluations of participatory platforms.

The first four design features are closely related to the democratic ideals outlined above as they concern features that influence how platforms empower citizens in political decision-making. The latter three concerns the user experience and are of a more practical nature to make the scenarios 
more realistic, although they also have consequences for how closely the platforms realize either of the democratic ideals.

The first design feature concerns the possibility for discussions, which is often considered one of the key advantages of participatory platforms (Bravo et al., 2019; Esau et al., 2020; Tambouris \& Gorilas, 2003). To include a possibility for discussions is clearly in line with the deliberative conceptualization of democracy, according to which citizens ought to develop their preferences through dialogue and rational assessment of their prior beliefs. However, this may require a facilitator or moderator to ensure that discussions are conducted in a civilized manner (Coleman \& Moss, 2012; Landwehr, 2014). While moderation improves the quality of discussions (Strandberg et al., 2017), online moderation is sensitive on government platforms due to fears that it leads to censorship (Wright, 2006). Hence, even when people realize that moderation can increase the quality of discussions, it cannot be taken for granted that they prefer this over unmoderated discussions.

Interaction with decision makers is the second design feature, which can be said to be in line with all three democratic ideals, although the participatory and deliberative ideals support more intensive interactions. Most platforms involve some form of interaction, if only in the sense of being able to submit questions to decision-makers (Christensen, 2013). An important difference is whether interaction occurs in real-time or is asynchronous, giving participants the time to contemplate the issues involved before asking further questions or adding comments(Coleman \& Moss, 2012, p. 8). Asynchronous interaction may increase the quality of deliberation on platforms, which is in line with a deliberative ideal (Esau et al., 2017). But the type of interaction is also important given that people are more likely to engage in reading text than writing it (Rhee \& Kim, 2009).

Availability of information is included as the third design feature. The easy dissemination of information, which is in line with all three democratic ideals, is considered one of the key advantages of ICTs (Coleman \& Blumler, 2009, p. 8). Disclosure of information helps empower citizens and hold officials responsible for any mismanagement of public resources (Kosack \& Fung, 2014, p. 66), and 
openness and transparency are generally considered prerequisites for a well-functioning democratic process (Bertot et al., 2010). Nevertheless, the provision of information can range from short, digested summaries to large-scale access to all information. While it might be said that more information is always preferable, citizens may prefer small pieces of information that make it possible to gain a quick overview over the proceedings.

The fourth design feature in the conjoint concerns the role of the platform in political decision-making, or how much influence citizens are afforded when using participatory platforms. Participatory platforms can play different roles in the decision-making process, which has direct consequences for the degree of policy influence afforded to citizens (Åström \& Grönlund, 2012). At one end of a continuum, platforms can allow citizens to make suggestions to decision makers, while at the other end, platforms can enable users to make final decisions that are directly implemented. While a more consultative role is in line with a representative democratic ideal, decision-making capacities are in line with a participatory democratic ideal. A deliberative ideal would occupy an intermediate position by emphasizing the possibility to discuss issues, trusting that all actors adapt their preferences accordingly. It remains unclear what citizens prefer for online platforms since studies show that it cannot be taken for granted that they favor stronger decision-making competences for participatory processes (Christensen, 2020).

The fifth design feature is type of verification, which immediately define how difficult it is for users to take part but can also indirectly affect the legitimacy of the platform. Public websites typically demand some form of identity verification, especially when allowing participants to provide input into formal political decision-making processes (Ma \& Agarwal, 2007; Mir et al., 2020; Mordini \& Green, 2009). The verification process can involve weak verification (for example sending a link to an email address that participants must click to verify their identity) or strong verification (use of official documents to verify identity). The dilemma here is that the authorities' demand for identity verification must respect the individual's right to privacy. While authorities have a legitimate interest in verifying that users are 
entitled to provide input, it is also important to ensure adequate protection of digital private data (Boehme-Neßler, 2016). Worries over security breaches may entail that people are reluctant to give authorities access to sensitive information needed for strong identity verification.

The sixth feature is related to this, since the possibility for anonymity has been a debated topic for online participation (Asenbaum, 2018; Moore et al., 2020; Nissenbaum, 1999). ${ }^{2}$ The right to anonymity constitutes an intrinsic democratic right when it comes to voting in elections, but the situation is very different when it comes to online participation. It has been debated whether people should be allowed to participate anonymously on public platforms and media sites, since anonymity has been shown to create an environment hostile to a sound democratic discussion (Cho \& Kwon, 2015). On the other hand, although making people identifiable can increase deliberative quality, it can also decrease engagement because people become less eager to contribute (Rhee \& Kim, 2009).

The seventh and final design feature involves the impact of accessibility, or whether the platform is available through a computer browser or in an application developed for these specific purposes (Desouza \& Bhagwatwar, 2012; Jäske \& Ertiö, 2019). The use of applications provide additional possibilities in a user environment developed for specific purposes, and may even help realize central democratic ideals (Jäske \& Ertiö, 2019). Nevertheless, it can from a user perspective be easier to access a participatory platform through a web browser that is readily available on any device, do not require installation, and do not pose additional risks of privacy breaches. This may especially be the case for less accustomed users, as depicted by the second aim in this study.

\subsection{Data, variables, and methods of analysis}

The data come from a survey distributed during 13 November-11 December 2019, which was filled in via Qualtrics by a sample of respondents ( $n=1048$ ) representative of the Finnish population when it

\footnotetext{
${ }^{2}$ Anonymity here concerns whether users reveal their identity to other users rather than the authorities behind the platform and is therefore distinct from the verification design feature.
} 
comes to age, gender, and region of living, as shown in Appendix A. ${ }^{3}$ Finland provides an interesting case for the present purposes as there is a relatively long history of providing possibilities for online participation via official platforms. The Finnish population may therefore be argued to be experienced in using ICTs for political purposes and therefore better able to determine what features they demand.

While the survey includes 1048 respondents, the unit of analysis in the statistical analyses is the number of profiles evaluated in total. This number can be calculated by multiplying the number of respondents (1048) by the number of profiles in each comparison (2) by the number of comparisons each respondent makes (6), which equals 12576 units of analysis. This makes it possible to handle the large number of possible combinations, as explained below.

The dependent variable is a dichotomous variable that take the value 1 if a given profile is chosen and 0 if it is not. The central independent variables are the design features, or attributes in conjoint terminology. These are measured as categorial variables indicating the values, or attribute levels, shown in each profile. The variables are represented by dummy variables for each design feature level, which makes it necessary to designate a reference category as indicated in Table 1 . In most cases, the reference category is the level that indicates absence of a feature, which means that the estimates can be understood as the effect of introducing a feature on the favorability of a platform. ${ }^{4}$

To assess the impact of the design features on platform favorability, I regress the platform choice on all design feature levels using OLS regression with clustered standard errors to account for the fact that platform choices are nested within respondents (Hainmueller et al., 2014). The coefficients obtained can be interpreted as the Average Marginal Component Effect (AMCE), which describes how much the probability of choosing a platform changes on average if a design feature was changed from the reference category to the particular attribute level (Hainmueller et al., 2014). Since there are 1728

\footnotetext{
${ }^{3}$ The use of an online panel for data collection mean that it is impossible to reach people who completely refrain from using the Internet. However, this problems is negligible considering that the use of the Internet is widespread in Finland, where $94 \%$ of all households had access to the Internet in 2018, compared to an EU-28 average of 89\% (Eurostat, 2020).

${ }^{4}$ For accessibility there are only two categories, meaning the effect simply indicates the difference between the platform being accessible via web browser or in an application.
} 
possible combinations of design feature levels in this study, it cannot be ascertained that all combinations are evaluated by a sufficiently large number of respondents, or even that all are observed. However, contrary to traditional factorial designs, conjoint analysis does not require that all possible combinations are observed to identify the AMCE of each component (Hainmueller et al., 2014).

It is not necessary to include control variables in the analyses since the randomization of the design features shown controls for possible confounding effects. However, since the estimated effects are population averages, it is important to establish whether the effects are similar across subgroups in the population since certain attributes may have stronger or weaker impacts depending on this (Abramson et al., 2019; Leeper et al., 2020). This is related to the aim of exploring differences across prior use of ICTs. Three respondent characteristics are used to examine differences across prior use of ICTs to gauge possible digital divides: Generations, time online and experience with using participatory platforms.

Generations is included since older generations are considered to be less willing or able to adopt new technology, whereas younger generation are digital natives who grew up with ICTs and therefore take the possibilities for granted (Bailey \& Ngwenyama, 2010; Howe \& Strauss, 2009). It is therefore likely that the effects of design features will differ across generations as the young have different expectations. While there is no universal agreement on the specific thresholds between generations, and other authors use slightly different years as thresholds (Taylor, 2016), respondents are here grouped by age into four categories with the following labels: Generation Z born 1995 or later: 18-24 years ( $\mathrm{n}=166$ respondents /1992 units of analysis), Millennials born 1980-1994: 25-39 years (288/3456), Generation X born 1965-1979: 40-54 years (309/3708), and Boomers born 1944-1964: 55- 
$75(285 / 3420) .{ }^{5}$ While Generation $Z$ is slightly smaller, as is the case in society, the three other generations have similar sizes.

It is also to be expected that effects differ depending on time online as accustomed users are likely to have different evaluations compared to those who use the Internet more rarely. To gauge this aspect respondents were asked how much time they are online on an average day (On an average day, how much time do you spend using the Internet?) with five answer categories: ${ }^{6}$ 'Less than 30 minutes a day' ( $n=12)$, '30-60 minutes'( $n=125)$, '1-2 hours' ( $n=259)$, '2-3 hours' $(n=290)$ and 'More than three hours a day' $(n=357)$. Few respondents indicated a low daily time online, and this variable was therefore recoded into three categories: Low online time (less than 2 hours), Intermediate online time (2-3 hours) and High online time (more than three hours).

Prior use of participatory platforms may also matter as those who are used to using these will have entirely differences needs and expectations than those who only occasionally made us of them. Respondents were asked about their prior use of several platforms available to citizens in Finland. ${ }^{7}$ For each of them, respondents had four answer possibilities: 'Never heard of', 'Heard of but never used', 'Used once or rarely', 'Use regularly'. The answers to all were combined into a composite index of prior use that ranged between $0-24$ (mean $=8.24, \mathrm{SD}=4.40$, Alpha $=0.81) .{ }^{8}$ This index as subsequently recoded into three categories of roughly equal sizes, where $0-6=$ Low use $(n=379), 7-9=$ Intermediate use $(n=322)$, and 10-24=High use $(n=347)$.

To inspect whether there are differences in effects depending on the prior use of ICTs, interaction terms between the design features and the relevant groups (generations, time online, and prior use of

\footnotetext{
${ }^{5}$ Millennials are sometimes referred to as Generation Y. I tested an alternative classification of age (30 or less, 31-42, 43-55, 56-75), and this led to similar substantial results. The exact demarcation is therefore unlikely to lead to different interpretations of the results in this case.

${ }^{6}$ Another question asked how often respondents used the Internet (Several times a day, once a day, less often than once a day), but the variation here was limited ( $0.76 \%$ used less than once a day and $93 \%$ several times a day) so this was not used. 7 The platforms included were: www.kansalaisaloite.fi, www.kuntalaisaloite.fi, www.demokratia.fi, www.nuortenideat.fi, www.otakantaa.fi, www.lasunto.fi, www.vaalit.fi, and the municipal homepage of the respondent. While some of these cater to special needs, most are general platforms available to all citizens in Finland.

${ }^{8} \mathrm{An}$ exploratory factor analysis indicated that the underlying structure was one-dimensional (eigenvalue factor $1=2.99$, factor $2=0.72$ ), which indicates that users do generally not specialize in certain types of platforms.
} 
platforms) are included to discern whether the causal effects differ across groups (Hainmueller et al., 2014). This average component interaction effect (ACIE) shows effect sizes for the different groups. To establish the substantial relevance of interaction effects, it is insufficient to rely on tests of significance (Kam \& Franzese, 2009, pp. 43-44). The practical implications are therefore also ascertained by seeing whether the effects have similar magnitudes and directions for different values of the moderator.

The AMCE and ACIE depend on what reference category is used in the analyses, which may be somewhat arbitrary and can lead to misleading interpretations when assessing differences across subgroups. It is therefore important to complement these with marginal means that are independent of the reference category chosen. This describes the level of favorability toward platforms with a particular feature level when ignoring all other features (Leeper et al., 2020). In other words, it expresses the proportion of times respondents pick platforms that include a given feature. For example, a value of 0.55 for anonymity means that respondents picked platforms that included this possibility $55 \%$ of the time it was shown. This would also entail that they prefer no possibility for anonymity $45 \%$ of the time since there are only these two possibilities for this design feature.

As recommended by Hainmueller et al (2014), all results are reported in coefficient plots, where estimates are indicated by dots and $95 \%$ confidence intervals show the uncertainty around this point estimate. For ACMEs and ACIEs, there is a vertical line at 0 . Point estimates to the right of this line indicate a positive $A C M E / A C I E$ and estimates to the left indicates a negative $A C M E / A C I E$. If the confidence intervals cross the line, it cannot be ruled out that the true estimate is zero. For the marginal means, the vertical line is at 0.5 , and when the intervals crosses this line, it means it cannot be ascertained that platforms incorporating this design feature are selected with a probability that deviates from the overall mean of 0.5 . The full regression results are included in Appendix C.

\section{Empirical analysis}

Figure 1 shows AMCEs and marginal means to address the first step in the analysis, which concerns the direct effects of the design features on evaluations of participatory platforms. 
Fig. 1. Effects of design features on evaluations (AMCEs and marginal means)
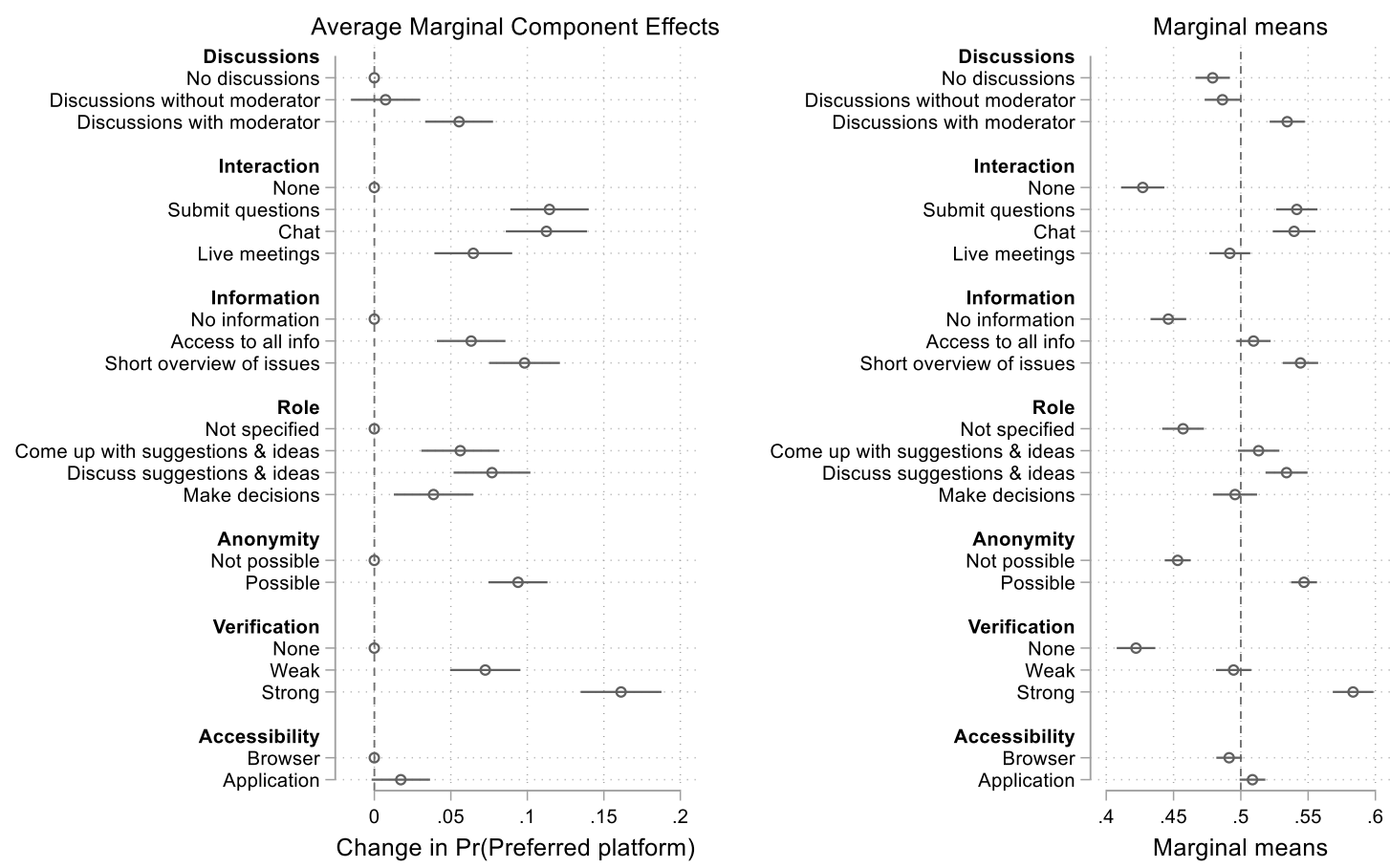

For possibilities for discussions, moderated discussions have a positive effect on favorability compared to no possibilities for discussions ( $A M C E=0.055, p=0.000$ ), which entails that the marginal mean moves from an average probability of being picked of 0.48 when no discussions are included to 0.53 when moderated discussions form part of a platform. The corresponding effect of discussions without moderation is not significant ( $\mathrm{AMCE}=0.01, \mathrm{p}=0.525)$.

All types of interaction with policy makers have positive effects, whether it is in the form of the possibility to submit questions ( $\mathrm{AMCE}=0.114, \mathrm{p}=0.000$ ), chatting $(\mathrm{AMCE}=0.112, p=0.000$ ) or live via web cams ( $\mathrm{AMCE}=0.064, \mathrm{p}=0.000$ ). However, only submitting questions and chatting have marginal means above 0.5 (both about 0.54 ), meaning platforms including these features have an above average favorability among respondents when ignoring other features.

For access to information, there are also positive effects of availability compared to no information, be it all available information ( $\mathrm{AMCE}=0.063, \mathrm{P}=0.000$ ) or a digested version which only contains an 
overview ( $\mathrm{AMCE}=0.098, \mathrm{P}=0.000$ ) However, it is only the latter digested version that respondents are more likely to select (mean $=0.54)$.

Respondents also prefer a specific role in decision-making, effects of being able to come up with suggestions ( $A M C E=0.065, p=0.000)$, discuss existing suggestions $(B=0.077, p=0.000)$ and taking decisions ( $A M C E=0.039, p=0.004)$. But the marginal means again reveal important differences as only the advisory roles of coming up with new ideas (Mean=0.51) and discussing existing ideas (Mean=0.53) are preferred by most respondents across other design features.

Including the possibility to remain anonymous has a positive effect ( $\mathrm{AMCE}=0.093, \mathrm{p}=0.000$ ), and such platforms a preferred by a majority (mean $=0.55)$. For verification, both weak $(B=0.07, p=0.000)$ and strong verification ( $\mathrm{AMCE}=0.16, \mathrm{p}=0.000$ ) have positive effects on favorability compared to having no verification system, but the marginal means show that only strong verification leads to an average level of favorability above 0.5 (mean=0.58). This design feature has the strongest effects of all, showing that verification is an important topic for prospective users. For accessibility on the other hand, it makes little difference whether the platform is delivered through an app or over an Internet browser $(\mathrm{AMCE}=0.02, p=0.075)$.

The following figures 2-4 show the results for $\mathrm{H} 2$ and differences across familiarity with the use of ICTs. Figure 2 shows differences in effects across generations. 
Fig. 2. ACIEs across generations
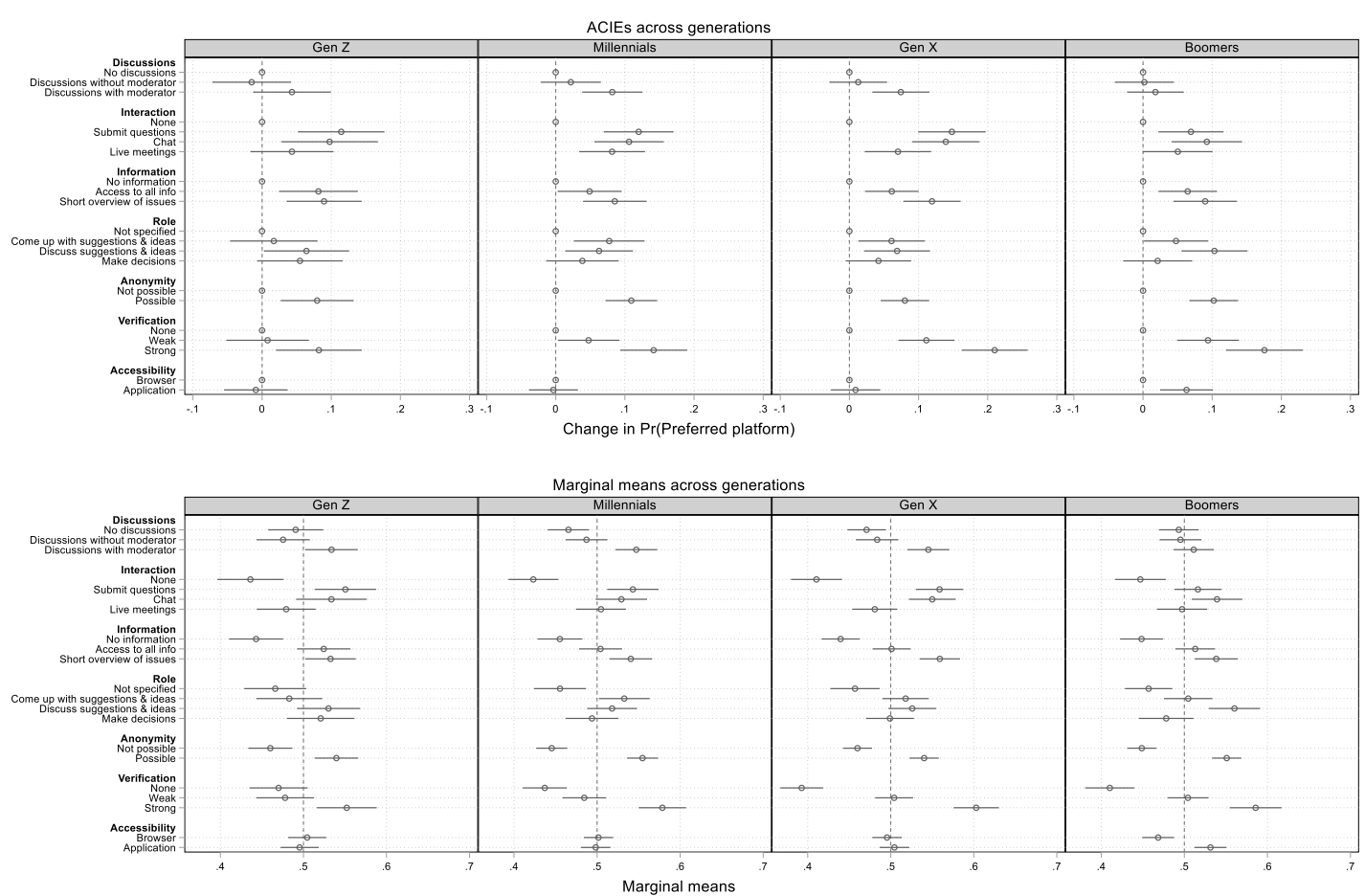

The main difference is for verification, where there are significant interaction effects for the effect of weak verification for Generation X (AMCE $=0.103, p=0.005)$ and Boomers $(A M C E=0.086, p=0.005)$ and for strong verification also for Generation X $(A M C E=0.128, p=0.001)$ and Boomers $(A M C E=0.093$, $p=0.027)$. This entails that verification has stronger effects for the older generations, whereas they are weaker for Generation Z, and to some extent the Millennials.

There is also a significant interaction effect for accessibility where the effect differ for Boomers ( $A M C E=0.072, p=0.017$ ), which entails that it has a stronger effect to allow access via an application rather than a computer browser for this generation.

Figure 3 shows the results depending on the time respondents are online on a daily basis. 
Fig. 3. ACIEs across time online
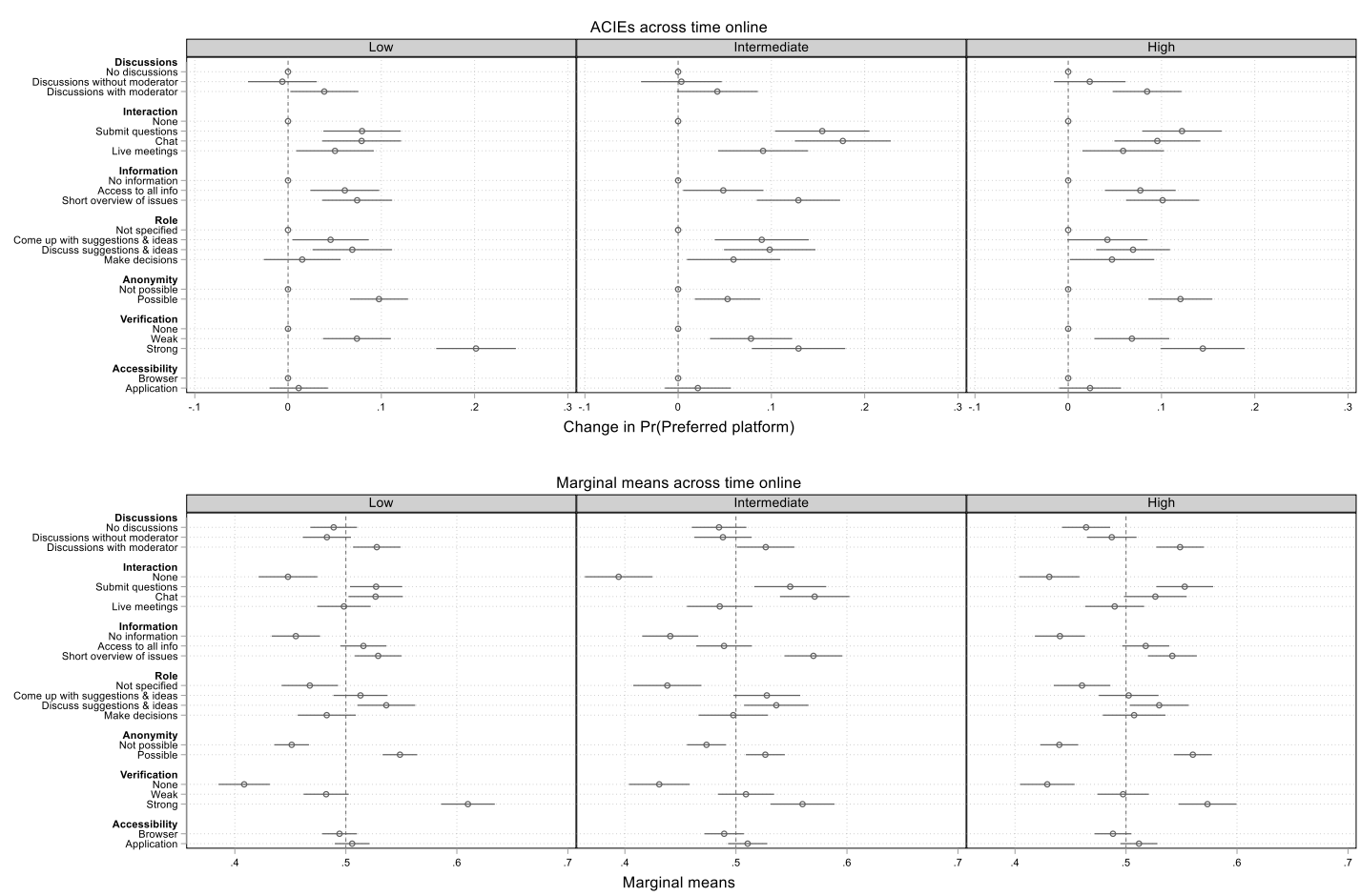

For discussions, an interaction effect between discussions with moderation and being online more than 3 hours a day approaches significance ( $A M C E=0.039, p=0.082$ ), but it is nonetheless noteworthy since it indicates that moderation is mainly demanded by those who are more online. Otherwise, it is often the intermediate group that stands out as several effects are or come close to close to being significant. For interactions with policy makers, the effects differ when it comes to submitting questions to ( $\mathrm{AMCE}=0.075, \mathrm{p}=0.024)$ and chatting with decision makers ( $\mathrm{AMCE}=0.098, \mathrm{p}=0.004$ ). However, the marginal means reveal that the stronger effects is mainly because platforms with no possibility for interaction are only picked $39.4 \%$ of the time among the intermediate users. For information, the interaction term for short overviews approaches significance in this group ( $\mathrm{AMCE}=0.055, \mathrm{p}=0.064)$, and this is also the case for allowing anonymity (AMCE $=-0.045, \mathrm{p}=0.062$ ). However, the practical implications here appear to be limited. Finally, the effect of strong verification also differs among those with intermediate daily use (AMCE $=-0.072, p=0.030$ ), and it even comes close to doing so in the group high daily usage ( $A M C E=-0.057, p=0.070)$. The main implication of this is that 
the group with low daily usage are more likely to pick a platform with strong verification (mean=0.61 compared to 0.56 for intermediate and 0.57 for those with high usage).

Figure 4 shows differences across prior use of participatory platforms.

Fig. 4. ACIEs across prior platform use
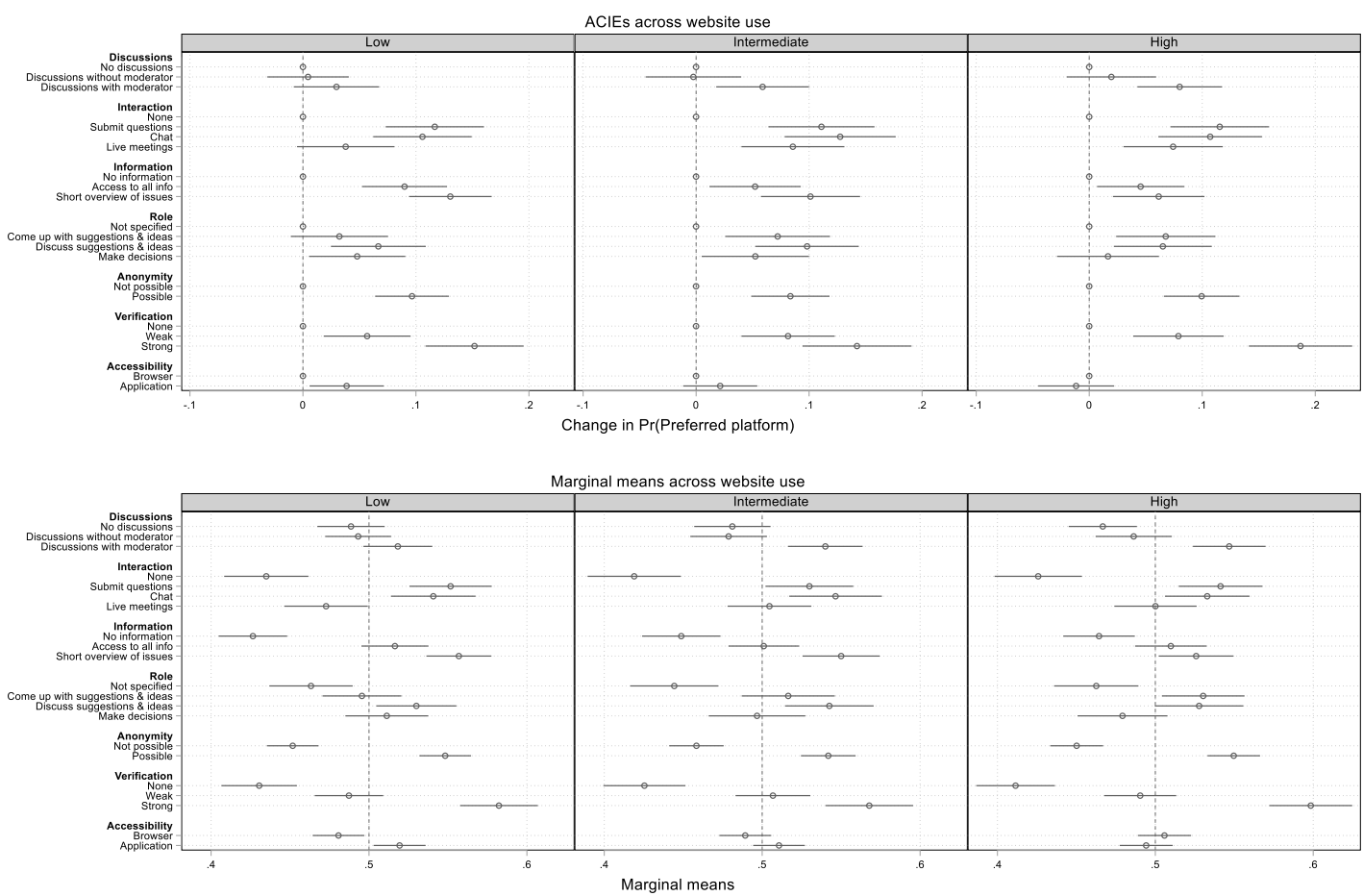

Here there are some indications that effects differ for the group most accustomed to using platforms.

The interaction effect with moderated discussions approaches significance (AMCE $=0.050, p=0.063$ ), which indicates that this design feature is more appreciated in this group. A significant interaction term for short information overviews shows that this feature is less appreciated among avid users (AMCE=0.069, $p=0.013$ ). Finally, a significant interaction effect for accessibility (AMCE $=-0.050, p=0.035$ ) entails that it is only among those with low prior involvement there is a positive effect for an application compared to accessing via the browser, whereas more accustomed users find this issue irrelevant since all effects are insignificant. 


\subsection{Robustness and assumptions}

This section examines factors that may weaken the validity of the results to ascertain the robustness of the results.

It may be objected that favorability does not imply that the design features also affect the willingness to participate. A follow-up question was therefore asked each time a respondent had indicated which platform they favored, asking them whether they would also participate on the selected platform. Fig. 5 shows the ACMES for this question. The marginal means are not shown since the follow-up question is only asked for the profile picked in the first place, which distorts the interpretation of the means.

Fig 5. Effects on willingness to participate

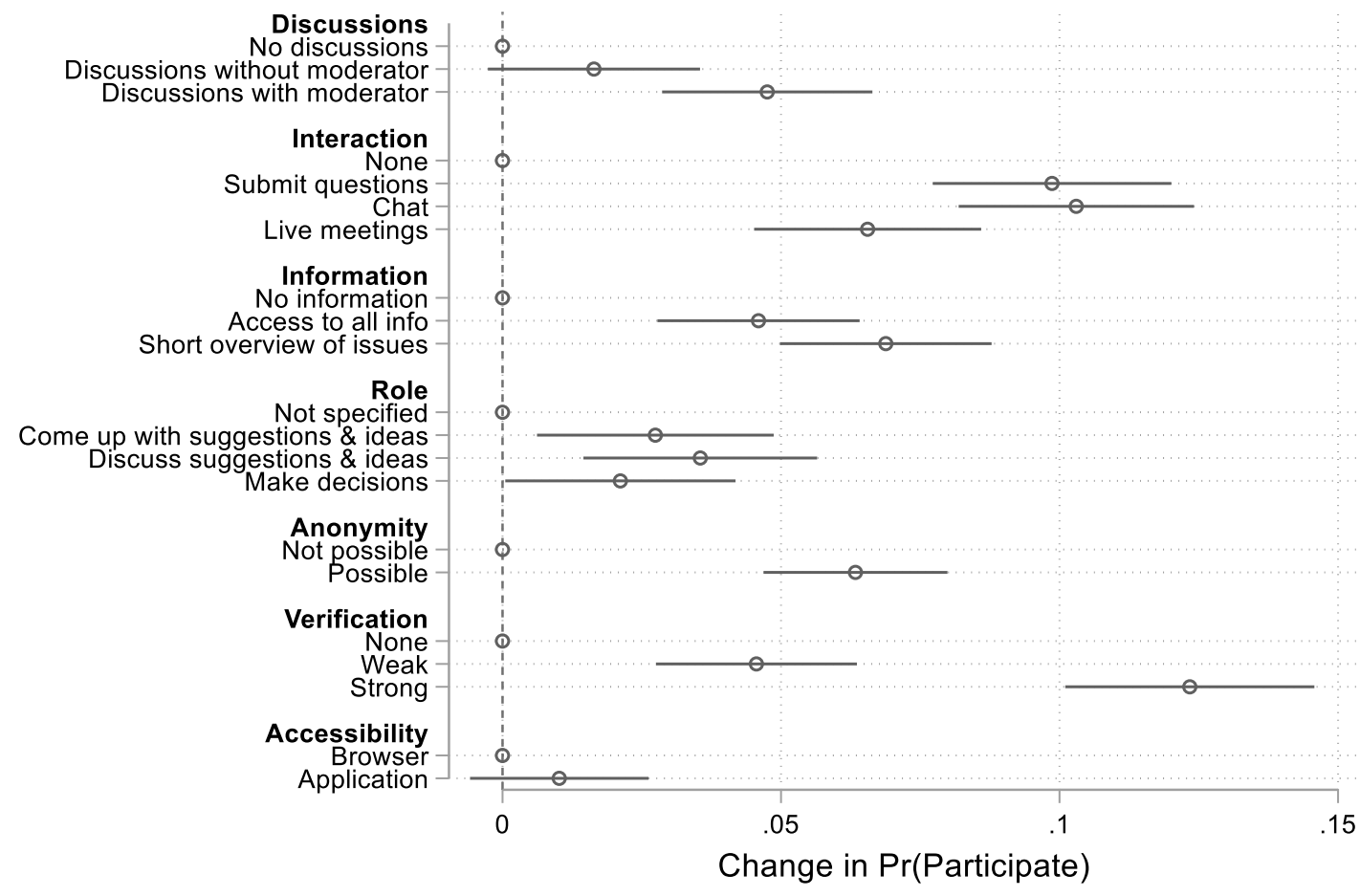

The pattern resembles the one shown in Figure 1, although the effects are weaker because selecting a platform in each comparison does not necessarily imply a willingness to also become active on this platform. Nevertheless, the results show that design features affect the willingness to participate in a similar manner. 
It is also important to assess the robustness of the results across the conjoint design (Hainmueller et al., 2014). While randomization can ensure that most features do not affect the results, it is necessary to examine differences across round of comparison and left/right profile. Figure 6 shows differences across the six rounds of comparisons to see whether there are patterns in the effects.

\section{Fig. 6. ACIEs across rounds of comparison}

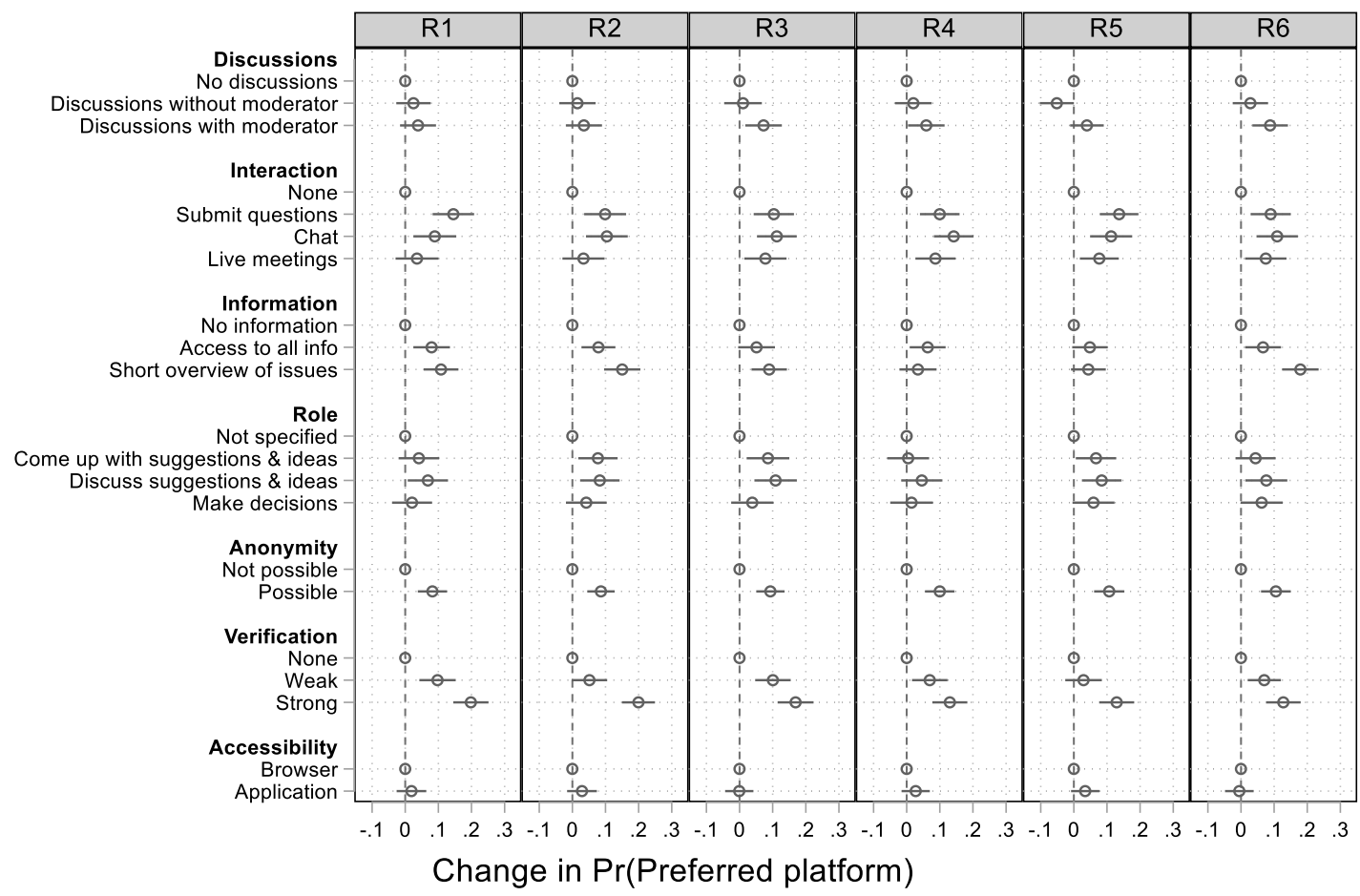

These results show that there are some fluctuations, and a tendency for strong verification to have weaker effects in round 4-6 (although none of the interaction effects are significant at a $p<0.05$ ). However, there is no uniform pattern towards weaker effects in the latter rounds, as would be expected if survey satisficing were affecting the results (Bansak et al., 2018). The results are therefore unlikely to be affected by respondents growing tired of comparing platforms.

The final check reported here concerns whether there are systematic differences depending on whether a profile was presented to the left or the right of the screen as this may also bias the results (Hainmueller et al., 2014). 
Fig. 7. ACIES across left/right placement

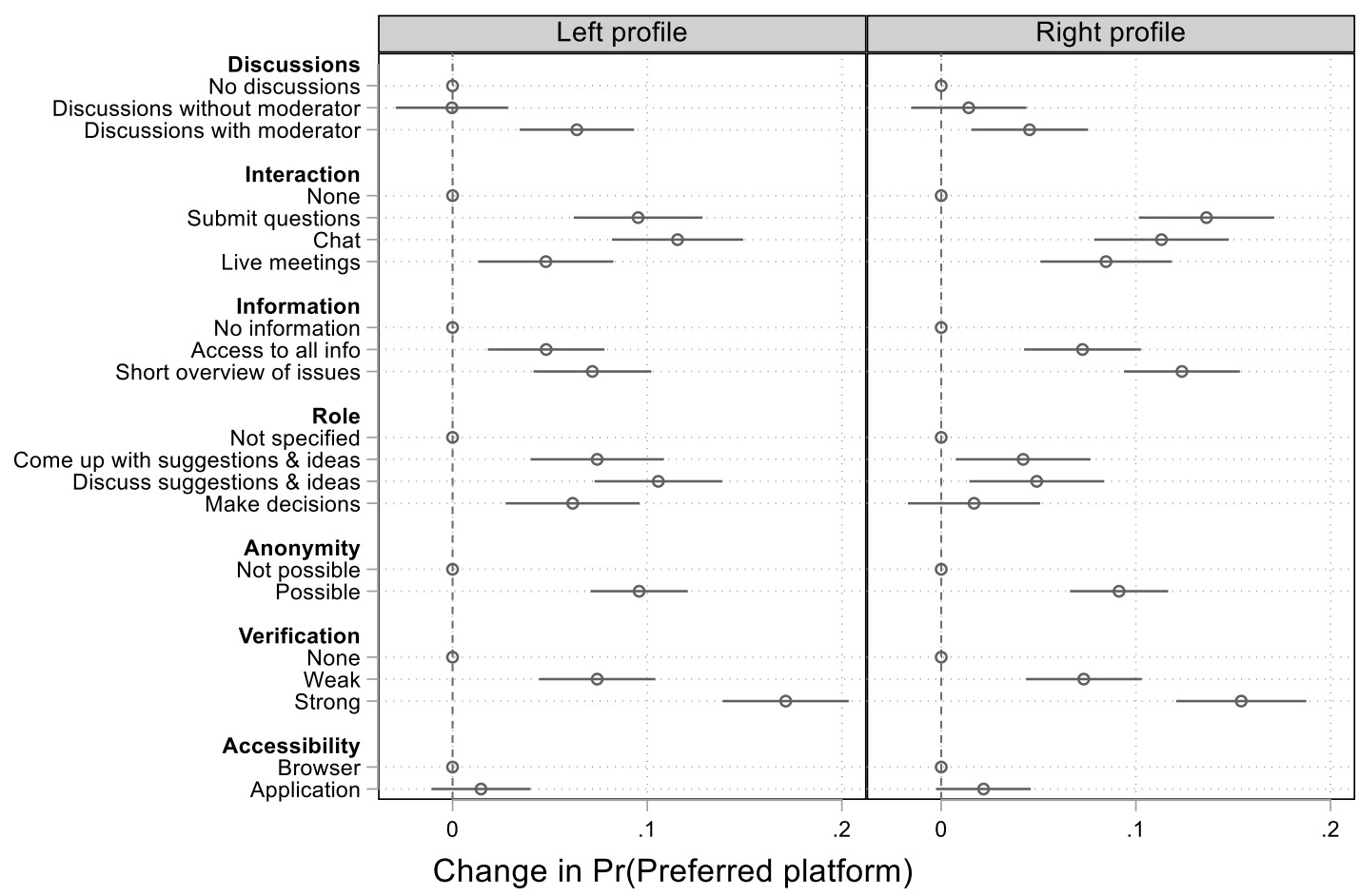

Here there is a tendency for the effects concerning all levels in role of the platform to be weaker when presented in the right pane rather than the left pane, which may have affected the impact of this design feature. However, because this is not the case for all other features, there is no reason to believe that this fluke biased the results.

\section{Discussion of results and conclusions}

This study has examined how design features affect evaluations of participatory platforms. The following highlights the main findings and their implications for how to successfully launch a participatory platform.

The results for $\mathrm{H} 1$ on the effects of design features on evaluations of participatory platforms clearly confirmed the hypotheses since the design features had noticeable consequences for how people evaluated the use of participatory platforms. Six of the seven design features affected favorability, the only exception being whether the platform was available through a browser or in an application. This 
shows that, as also highlighted by previous studies, design matters for the impact of participatory platforms platform (Åström \& Grönlund, 2012; Esau et al., 2017; Fung, 2003; Steibel \& Estevez, 2015). However, this research goes beyond the previous endeavors to show that design features directly affect how citizens, and thereby prospective users, evaluate the usefulness of such platforms and even their willingness to participate on them. The results clearly demonstrate that it has negative consequences when features are missing, as indicated by the mean scores in Figure 1. Accordingly, people have less favorable evaluations of platforms that do not include key features, which implies that creators of new participatory platforms should carefully consider what the public want rather than rely solely on abstract ideals or technological possibilities.

However, there are also important differences between the design features in how strongly they affect evaluations, which can be connected to the three democratic ideals of representative democracy, participatory democracy, and deliberative democracy. The results show that deliberative design features have the most consistent positive effects on evaluations, which is in line with previous studies that emphasize the need to increase the deliberativeness of participatory platforms (Coleman \& Moss, 2012; Esau et al., 2017; Fishkin, 2009; Landwehr, 2014; Neblo et al., 2018; Rhee \& Kim, 2009). The clearest evidence is that a possibility for moderated discussions affects evaluations in a positive manner, but also the positive effect of being able to discuss suggestions and ideas rather than make decisions is in line with the deliberative democratic ideal. While it may seem surprising that people prefer platforms incorporating such demanding features, similar results have been found for offline participatory mechanisms, where people also prefer processes that incorporate deliberate aspects (Christensen, 2020). This means that participatory platforms should aim to include deliberative features that enable respectful dialogue and careful contemplation of the pros and cons of the issues under consideration. It may therefore be worrying that online platforms introduced by authorities often mainly include features in line with representative and participatory democratic ideals 
(Christensen, 2013). That online platforms fail to deliver what citizens want may help explain why they frequently fail to mobilize citizens (Anthopoulos et al., 2016; Elkadi, 2013; Toots, 2019).

The more pragmatic features under scrutiny were also important, and the effects were as strong or even stronger in the case of verification. The results show that a high level of identity verification has a positive effect on evaluations (Ma \& Agarwal, 2007; Mir et al., 2020; Mordini \& Green, 2009), but people also value the possibility to remain anonymous (Asenbaum, 2018; Moore et al., 2020; Nissenbaum, 1999). While these two results may seem contradictory, it is entirely possible for people to trust authorities with their private information without wanting to share their identity with other users. Platform developers should therefore aim to develop platforms that enable strong verification, but also give users the possibility to not disclose their identity to other users, for example during discussions.

The second hypothesis was also supported since differences exist among people depending on their prior use of ICTs. This shows that there are risks of creating digital divides when initiators do not consider differences in the previous experiences of users. Nevertheless, while differences existed, they were less acute than what the most dire interpretations of the digital divide suggest (Dijk, 2005; DiMaggio \& Garip, 2012; Norris, 2001; Warschauer, 2004). The results were similar when it came to the roles of citizens imagined on the platforms, while the clearest difference concerned the use of verification. That the effects were stronger among less accustomed users can most likely be explained by people without experience worrying more about security issues. To mobilize these users, it is therefore important to create platforms that can alleviate such fears.

\subsection{Conclusion}

These results clearly show that it is important to consider a user perspective when launching a participatory platform. What design features are included has direct implications for how citizens assess the usefulness of participatory platforms, and, although in a more diluted form, their willingness to participate on them. Inattention to this aspect may help explain why platforms fail to deliver on their promises (Anthopoulos et al., 2016; Choi \& Chandler, 2020; Elkadi, 2013; Toots, 2019). Even when 
it may not make sense to ask users directly, it is important to find alternative ways to gauge how citizens evaluate features of participatory platforms. Survey experiments such as conjoint analysis may provide a useful tool to gain an insight into subjective evaluations that people are unwilling or unable to articulate when asked directly.

More substantially, the results emphasize the importance of building participatory platforms that incorporate deliberative design features. This is important for practitioners, who ought to ensure that deliberative features are embedded in participatory platforms to ensure free-flowing communication and deliberation among all stakeholders. For researchers, it becomes important to study what mechanisms can best ensure that platforms live up to the deliberative ideals. The roles of moderation and anonymity provide examples of features where it is still unclear how these can best be implemented in accordance with a deliberative ideal.

While these findings thus provide important insights, it is still necessary to assess whether similar effects can be replicated outside of Finland. Although the results here do not reveal major differences across groups in the population, it cannot be taken for granted that this is also the case in countries where the population is less accustomed to participatory platforms. It is important to consider contextual differences in this regard, which should be a key concern for future research. Another important aim for future research is to discern whether similar results can be found across different kinds of platforms, also those that do not have explicit political purposes.

Funding: This work was supported by the Academy of Finland [Grant number 285167]. 


\section{References}

Abramson, S. F., Koçak, K., \& Magazinnik, A. (2019). What Do We Learn About Voter Preferences From

Conjoint Experiments? Unpublished manuscript. https://pdfs.semanticscholar.org/023a/24a7dfaddfce626d011596b187f26361ee86.pdf

Anthopoulos, L., Reddick, C. G., Giannakidou, I., \& Mavridis, N. (2016). Why e-government projects fail? An analysis of the Healthcare.gov website. Government Information Quarterly, 33(1), 161-173. https://doi.org/10.1016/j.giq.2015.07.003

Anttiroiko, A.-V., Valkama, P., \& Bailey, S. J. (2014). Smart cities in the new service economy: Building platforms for smart services. Al \& SOCIETY, 29(3), 323-334. https://doi.org/10.1007/s00146013-0464-0

Asenbaum, H. (2018). Anonymity and Democracy: Absence as Presence in the Public Sphere. American Political Science Review, 112(3), 459-472. https://doi.org/10.1017/\$0003055418000163

Åström, J., \& Grönlund, Å. (2012). Online Consultation in Local government: What works, When, and Why? In S. Coleman \& P. M. Shane (Eds.), Connecting Democracy: Online Consultation and the Flow of Political Communication (pp. 75-96). MIT Press.

Bailey, A., \& Ngwenyama, O. (2010). Bridging the Generation Gap in ICT Use: Interrogating Identity, Technology and Interactions in Community Telecenters. Information Technology for Development, 16(1), 62-82. https://doi.org/10.1080/02681100903566156

Bansak, K., Hainmueller, J., Hopkins, D. J., \& Yamamoto, T. (2018). The Number of Choice Tasks and Survey Satisficing in Conjoint Experiments. Political Analysis, 26(1), 112-119. https://doi.org/10.1017/pan.2017.40

Bengtsson, Å., \& Christensen, H. S. (2016). Ideals and Actions: Do Citizens' Patterns of Political Participation Correspond to their Conceptions of Democracy? Government and Opposition, 51(02), 234-260. https://doi.org/10.1017/gov.2014.29 
Bertot, J. C., Jaeger, P. T., \& Grimes, J. M. (2010). Using ICTs to create a culture of transparency: Egovernment and social media as openness and anti-corruption tools for societies. Government Information Quarterly, 27(3), 264-271. https://doi.org/10.1016/j.giq.2010.03.001

Boehme-Neßler, V. (2016). Privacy: A matter of democracy. Why democracy needs privacy and data protection. International Data Privacy Law, 6(3), 222-229. https://doi.org/10.1093/idpl/ipw007

Bravo, R. B., Balcells, J., \& Padró-Solanet, A. (2019). Platform Politics in Europe | A Model for the Analysis of Online Citizen Deliberation: Barcelona Case Study. International Journal of Communication, 13(0), 25.

Chadwick, A. (2003). Bringing E-Democracy Back In: Why it Matters for Future Research on EGovernance. Social Science Computer Review, 21(4), 443-455.

Chambers, S. (2003). Deliberative Democratic Theory. Annual Review of Political Science, 6(1), 307326. https://doi.org/10.1146/annurev.polisci.6.121901.085538

Cho, D., \& Kwon, K. H. (2015). The impacts of identity verification and disclosure of social cues on flaming in online user comments. Computers in Human Behavior, 51, 363-372. https://doi.org/10.1016/j.chb.2015.04.046

Choi, T., \& Chandler, S. M. (2020). Knowledge vacuum: An organizational learning dynamic of how egovernment innovations fail. Government Information Quarterly, 37(1), 101416. https://doi.org/10.1016/j.giq.2019.101416

Christensen, H. S. (2013). Broadening Democratic Participation? An exploratory study of e-democracy in 188 Finnish municipalities. Scandinavian Journal of Public Administration, 17(3), 3-21.

Christensen, H. S. (2020). How citizens evaluate participatory processes: A conjoint analysis. European Political Science Review, 12(2), 239-253. https://doi.org/10.1017/S1755773920000107

Coleman, S., \& Blumler, J. G. (2009). The Internet and Democratic Citizenship: Theory, Practice and Policy. Cambridge University Press. 
Coleman, S., \& Moss, G. (2012). Under Construction: The Field of Online Deliberation Research. Journal of Information Technology \& Politics, 9(1), 1-15. https://doi.org/10.1080/19331681.2011.635957

Coleman, S., \& Shane, P. M. (Eds.). (2012). Connecting Democracy: Online Consultation and the Flow of Political Communication. MIT Press.

Dahl, R. A. (1989). Democracy and Its Critics. Yale University Press.

Dahlberg, L. (2001). The Internet and Democratic Discourse: Exploring The Prospects of Online Deliberative Forums Extending the Public Sphere. Information, Communication \& Society, 4(4), 615-633. https://doi.org/10.1080/13691180110097030

Dahlgren, P. (2005). The Internet, Public Spheres, and Political Communication: Dispersion and $\begin{array}{llll}\text { Deliberation. } & \text { Political } & \text { 22(2), }\end{array}$ https://doi.org/10.1080/10584600590933160

Desouza, K. C., \& Bhagwatwar, A. (2012). Citizen Apps to Solve Complex Urban Problems. Journal of Urban Technology, 19(3), 107-136. https://doi.org/10.1080/10630732.2012.673056

Dijk, J. A. G. M. van. (2005). The Deepening Divide: Inequality in the Information Society. SAGE Publications.

DiMaggio, P., \& Garip, F. (2012). Network Effects and Social Inequality. Annual Review of Sociology, 38(1), 93-118. https://doi.org/10.1146/annurev.soc.012809.102545

Dutton, W. H. (1992). Political Science Research on Teledemocracy. Social Science Computer Review, 10(4), 505-522. https://doi.org/10.1177/089443939201000405

Elkadi, H. (2013). Success and failure factors for e-government projects: A case from Egypt. Egyptian Informatics Journal, 14(2), 165-173. https://doi.org/10.1016/j.eij.2013.06.002

Esau, K., Fleuß, D., \& Nienhaus, S.-M. (2020). Different Arenas, Different Deliberative Quality? Using a Systemic Framework to Evaluate Online Deliberation on Immigration Policy in Germany. Policy \& Internet. https://doi.org/10.1002/poi3.232 
Esau, K., Friess, D., \& Eilders, C. (2017). Design Matters! An Empirical Analysis of Online Deliberation on Different News Platforms. Policy \& Internet, 9(3), 321-342. https://doi.org/10.1002/poi3.154

Eurostat. (2020). Digital Economy and Society Statistics - Households and Individuals. https://ec.europa.eu/eurostat/statistics-

explained/index.php/Digital_economy_and_society_statistics_-_households_and_individuals

Fishkin, J. (2009). When the People Speak: Deliberative Democracy and Public Consultation. Oxford University Press.

Fung, A. (2003). Survey Article: Recipes for Public Spheres: Eight Institutional Design Choices and Their Consequences. Journal of Political Philosophy, 11(3), 338-367. https://doi.org/10.1111/14679760.00181

Hainmueller, J., Hopkins, D. J., \& Yamamoto, T. (2014). Causal Inference in Conjoint Analysis: Understanding Multidimensional Choices via Stated Preference Experiments. Political Analysis, 22(01), 1-30. https://doi.org/10.1093/pan/mpt024

Held, D. (2006). Models of Democracy (3rd ed.). Stanford University Press.

Holden, S., Norris, D. F., \& Fletcher, P. D. (2003). Electronic Government at the Local Level. Public $\begin{array}{lll}\text { Performance \& } \quad \text { Management } & \text { 26(4), 325-344. }\end{array}$ https://doi.org/10.1177/1530957603252580

Howe, N., \& Strauss, W. (2009). Millennials Rising: The Next Great Generation. Knopf Doubleday Publishing Group.

Jäske, M., \& Ertiö, T. (2019). The democratic potential of civic applications. Information Polity, 24(1), 21-39. https://doi.org/10.3233/IP-180105

Kam, C., \& Franzese, R. J. (2009). Modeling and Interpreting Interactive Hypotheses in Regression Analysis. University of Michigan Press.

Kitsing, M. (2011). Success Without Strategy: E-Government Development in Estonia. Policy \& Internet, 3(1), 86-106. https://doi.org/10.2202/1944-2866.1095 
Kosack, S., \& Fung, A. (2014). Does Transparency Improve Governance? Annual Review of Political Science, 17(1), 65-87. https://doi.org/10.1146/annurev-polisci-032210-144356

Landwehr, C. (2014). Facilitating Deliberation: The Role of Impartial Intermediaries in Deliberative Mini-Publics. In K. Grönlund, A. Bächtiger, \& M. Setälä (Eds.), Deliberative Mini-Publics: Involving Citizens in the Democratic Process (pp. 77-92). ECPR Press.

Leeper, T. J., Hobolt, S. B., \& Tilley, J. (2020). Measuring Subgroup Preferences in Conjoint Experiments. Political Analysis, 28(2), 207-221. https://doi.org/10.1017/pan.2019.30

Lim, J. H. (2010). Digital Divides in Urban E-Government in South Korea: Exploring Differences in Municipalities' Use of the Internet for Environmental Governance. Policy \& Internet, 2(3), 3168. https://doi.org/10.2202/1944-2866.1051

Ma, M., \& Agarwal, R. (2007). Through a Glass Darkly: Information Technology Design, Identity Verification, and Knowledge Contribution in Online Communities. Information Systems Research, 18(1), 42-67. https://doi.org/10.1287/isre.1070.0113

Manoharan, A., \& Holzer, M. (Eds.). (2012). Active Citizen Participation in E-Government: A Global Perspective. IGI Global. www.igi-global.com/book/active-citizen-participationgovernment/58264

Mir, U. B., Kar, A. K., Dwivedi, Y. K., Gupta, M. P., \& Sharma, R. S. (2020). Realizing digital identity in government: Prioritizing design and implementation objectives for Aadhaar in India. Government Information Quarterly, 37(2), 101442. https://doi.org/10.1016/j.giq.2019.101442

Moore, A., Fredheim, R., Wyss, D., \& Beste, S. (2020). Deliberation and Identity Rules: The Effect of Anonymity, Pseudonyms and Real-Name Requirements on the Cognitive Complexity of Online News Comments: Political Studies. https://doi.org/10.1177/0032321719891385

Mordini, E., \& Green, M. (Eds.). (2009). Identity, Security and Democracy: The Wider Social and Ethical Implications of Automated Systems for Human Identification. IOS Press.

Neblo, M. A., Esterling, K. M., \& Lazer, D. (2018). Politics with the people: Building a directly representative democracy. Cambridge University Press. 
Nielsen, J., \& Pernice, K. (2010). Eyetracking Web Usability. New Riders.

Nissenbaum, H. (1999). The Meaning of Anonymity in an Information Age. The Information Society, 15(2), 141-144. https://doi.org/10.1080/019722499128592

Norris, P. (2001). Digital Divide: Civic Engagement, Information Poverty, and the Internet Worldwide. Cambridge University Press.

Päivärinta, T., \& Sæbø, Ø. (2006). Models of E-Democracy. Communications of the Association for Information Systems, 17(1). https://doi.org/10.17705/1CAIS.01737

Panopoulou, E., Tambouris, E., \& Tarabanis, K. (2018). An eParticipation acceptance model. IEEE Transactions on Emerging Topics in Computing, 1-1. https://doi.org/10.1109/TETC.2018.2861426

Pateman, C. (1970). Participation and Democratic Theory. Cambridge University Press.

Rhee, J. W., \& Kim, E.-M. (2009). Deliberation on the Net: Lessons from a Field Experiment. In T. Davies \& S. P. Gangadharan (Eds.), Online Deliberation: Design, Research and Practice (pp. 223-232). University of Chicago Press.

Steibel, F., \& Estevez, E. (2015). Designing Web 2.0 Tools for Online Public Consultation. In A. Chib, J. May, \& R. Barrantes (Eds.), Impact of Information Society Research in the Global South (pp. 243-263). Springer. https://doi.org/10.1007/978-981-287-381-1_13

Strandberg, K., Himmelroos, S., \& Grönlund, K. (2017). Do discussions in like-minded groups necessarily lead to more extreme opinions? Deliberative democracy and group polarization. International Political Science Review.

Tambouris, E., \& Gorilas, S. (2003). Evaluation of an e-democracy Platform for European Cities. In R. Traunmüller (Ed.), Electronic Government (pp. 43-48). Springer. https://doi.org/10.1007/10929179_7

Taylor, P. (2016). The Next America: Boomers, Millennials, and the Looming Generational Showdown. Hachette UK. 
Toots, M. (2019). Why E-participation systems fail: The case of Estonia's Osale.ee. Government Information Quarterly, 36(3), 546-559. https://doi.org/10.1016/j.giq.2019.02.002

United Nations. (2018). 2018 E-government survey: Gearing e-government to support transformation towards sustainable and resilient societies. United Nations.

Warschauer, M. (2004). Technology and Social Inclusion: Rethinking the Digital Divide. MIT Press.

Wright, S. (2006). Government-run Online Discussion Fora: Moderation, Censorship and the Shadow of Control. The British Journal of Politics and International Relations, 8(4), 550-568. https://doi.org/10.1111/j.1467-856x.2006.00247.x

Zaller, J. R. (1992). The Nature and Origins of Mass Opinion. Cambridge University Press. https://doi.org/10.1017/СВ09780511818691 


\section{Appendix A: Respondent characteristics}

Table A1 shows the characteristics of the respondents compared to the general population in Finland.

Table A1. Respondent characteristics

\begin{tabular}{lcc}
\hline \multicolumn{1}{c}{$\mathbf{n = 1 0 4 8}$} & Sample & $\begin{array}{c}\text { Finnish population } \\
\text { (excluding Åland islands) } \\
\text { \% }\end{array}$ \\
\hline Age & & 23.0 \\
$\mathbf{1 8 - 2 9}$ & 23.9 & 19.0 \\
$\mathbf{3 0 - 3 9}$ & 19.3 & 18.0 \\
$\mathbf{4 0 - 4 9}$ & 18.5 & 20.0 \\
$\mathbf{5 0 - 5 9}$ & 20.4 & 20.0 \\
$\mathbf{6 0 - 6 9}$ & 17.9 & 50.0 \\
Gender & & 50.0 \\
$\quad$ Male & 48.7 & 30.0 \\
Female & 51.3 & 24.0 \\
Region & 29.8 & 21.0 \\
Helsinki area & 24.4 & 25.0 \\
Northern and Eastern Finland & 20.4 & \\
Southern Finland & 25.4 & \\
Western Finland & & \\
\hline
\end{tabular}

Since there were no major differences between the sample and the general population, no weighting was applied during the analyses. 


\section{Appendix B: The conjoint in Qualtrics}

The screenshot below shows an example of how the conjoint experiment appeared in Qualtrics. For clarity, this has been translated into English although the original version was shown in Finnish.

\section{Fig. A.1 Screenshot from Qualtrics of the conjoint experiment (translated into English)}

(1/6) Please select the platform you would like to see introduced

\begin{tabular}{|c|c|c|}
\hline & Platform 1 & Platform 2 \\
\hline $\begin{array}{l}\text { Verification of the identifies of } \\
\text { participants }\end{array}$ & $\begin{array}{l}\text { Strong verification with bank } \\
\text { codes or personal id }\end{array}$ & No verification \\
\hline $\begin{array}{l}\text { Possibility to participate } \\
\text { anonymously }\end{array}$ & No & No \\
\hline $\begin{array}{l}\text { Possibilities for discussions among } \\
\text { participants }\end{array}$ & $\begin{array}{l}\text { Discussions between participants } \\
\text { supervised by a neutral moderator }\end{array}$ & $\begin{array}{l}\text { Discussions between participants } \\
\text { supervised by a neutral } \\
\text { moderator }\end{array}$ \\
\hline $\begin{array}{l}\text { Possibilities for interaction with } \\
\text { politicians and experts }\end{array}$ & $\begin{array}{l}\text { Chat questions to experts and } \\
\text { politicians that are answered } \\
\text { immediately }\end{array}$ & No interaction \\
\hline Availability of information & No information is available & $\begin{array}{l}\text { Short overview of important } \\
\text { issues in connection to decisions }\end{array}$ \\
\hline The main goal of participation & $\begin{array}{l}\text { Discuss existing suggestions and } \\
\text { ideas }\end{array}$ & $\begin{array}{l}\text { Come up with new suggestions } \\
\text { and ideas }\end{array}$ \\
\hline Possibilities for accessing platform & Via Internet browser on computer & $\begin{array}{l}\text { In an application for phones and } \\
\text { tablets }\end{array}$ \\
\hline
\end{tabular}




\section{Appendix C: Regression results}

Table A2. Regressions results

\begin{tabular}{|c|c|c|c|c|}
\hline & ACME & $\begin{array}{c}\text { Interaction with } \\
\text { generation }\end{array}$ & $\begin{array}{l}\text { Interaction with } \\
\text { time online }\end{array}$ & $\begin{array}{l}\text { Interaction with } \\
\text { prior website use }\end{array}$ \\
\hline \multicolumn{5}{|l|}{ Discussion (Ref: No discussions) } \\
\hline Discussions without moderation & $\begin{array}{c}0.007 \\
(0.011)\end{array}$ & $\begin{array}{l}-0.015 \\
(0.029)\end{array}$ & $\begin{array}{l}-0.006 \\
(0.019)\end{array}$ & $\begin{array}{c}0.005 \\
(0.018)\end{array}$ \\
\hline Discussions with moderation & $\begin{array}{c}0.055^{* * *} \\
(0.011)\end{array}$ & $\begin{array}{c}0.043 \\
(0.028)\end{array}$ & $\begin{array}{r}0.039 * * \\
(0.019)\end{array}$ & $\begin{array}{c}0.030 \\
(0.019)\end{array}$ \\
\hline \multicolumn{5}{|l|}{ Interaction (Ref. No interaction) } \\
\hline Submit questions & $\begin{array}{c}0.114^{* * *} \\
(0.013)\end{array}$ & $\begin{array}{c}0.114^{* * *} \\
(0.032)\end{array}$ & $\begin{array}{c}0.079 * * * \\
(0.021)\end{array}$ & $\begin{array}{c}0.117^{* * *} \\
(0.022)\end{array}$ \\
\hline Chat questions & $\begin{array}{c}0.112 * * * \\
(0.014)\end{array}$ & $\begin{array}{c}0.098^{* * *} \\
(0.035)\end{array}$ & $\begin{array}{c}0.079 * * * \\
(0.021)\end{array}$ & $\begin{array}{c}0.106 * * * \\
(0.022)\end{array}$ \\
\hline Live questions & $\begin{array}{c}0.065 * * * \\
(0.013)\end{array}$ & $\begin{array}{l}0.043 \\
(0.030)\end{array}$ & $\begin{array}{c}0.050^{* *} \\
(0.021)\end{array}$ & $\begin{array}{l}0.038^{*} \\
(0.022)\end{array}$ \\
\hline \multicolumn{5}{|l|}{ Information (Ref. No information) } \\
\hline All information & $\begin{array}{c}0.063 * * * \\
(0.011)\end{array}$ & $\begin{array}{c}0.081^{* * *} \\
(0.029)\end{array}$ & $\begin{array}{c}0.061^{* * *} \\
(0.019)\end{array}$ & $\begin{array}{c}0.090 * * * \\
(0.019)\end{array}$ \\
\hline Overview & $\begin{array}{c}0.098^{* * *} \\
(0.012)\end{array}$ & $\begin{array}{c}0.090 * * * \\
(0.027)\end{array}$ & $\begin{array}{c}0.074^{* * *} \\
(0.019)\end{array}$ & $\begin{array}{c}0.130 * * * \\
(0.019)\end{array}$ \\
\hline \multicolumn{5}{|l|}{ Role (Ref undefined) } \\
\hline Come up with ideas & $\begin{array}{c}0.056 * * * \\
(0.013)\end{array}$ & $\begin{array}{l}0.017 \\
(0.032)\end{array}$ & $\begin{array}{c}0.046^{* *} \\
(0.021)\end{array}$ & $\begin{array}{c}0.032 \\
(0.022)\end{array}$ \\
\hline Discuss existing ideas & $\begin{array}{c}0.077^{* * *} \\
(0.013)\end{array}$ & $\begin{array}{c}0.064^{* *} \\
(0.031)\end{array}$ & $\begin{array}{c}0.069 * * * \\
(0.022)\end{array}$ & $\begin{array}{c}0.067 * * * \\
(0.021)\end{array}$ \\
\hline Make final decisions & $\begin{array}{c}0.039 * * * \\
(0.013)\end{array}$ & $\begin{array}{l}0.055^{*} \\
(0.031)\end{array}$ & $\begin{array}{c}0.015 \\
(0.021)\end{array}$ & $\begin{array}{c}0.048^{* *} \\
(0.022)\end{array}$ \\
\hline Anonymity (Ref. Not possible) & $\begin{array}{c}0.094^{* * *} \\
(0.010)\end{array}$ & $\begin{array}{c}0.080 * * * \\
(0.027)\end{array}$ & $\begin{array}{c}0.098 * * * \\
(0.016)\end{array}$ & $\begin{array}{c}0.097 * * * \\
(0.017)\end{array}$ \\
\hline \multicolumn{5}{|l|}{ Verification (Ref. No verification) } \\
\hline Weak verification & $\begin{array}{c}0.073 * * * \\
(0.012)\end{array}$ & $\begin{array}{l}0.008 \\
(0.030)\end{array}$ & $\begin{array}{c}0.074 * * * \\
(0.018)\end{array}$ & $\begin{array}{c}0.057^{* * *} \\
(0.020)\end{array}$ \\
\hline Strong accessibility & $\begin{array}{c}0.161 * * * \\
(0.013)\end{array}$ & $\begin{array}{c}0.082 * * * \\
(0.031)\end{array}$ & $\begin{array}{c}0.202 * * * \\
(0.022)\end{array}$ & $\begin{array}{c}0.152^{* * *} \\
(0.022)\end{array}$ \\
\hline $\begin{array}{l}\text { Accessibility (Ref. Web browser) } \\
\text { Generation (Ref Gen Z) }\end{array}$ & \multicolumn{3}{|c|}{ Generation (Ref Gen Z) } & $0.039 * *$ \\
\hline Millennials & & $\begin{array}{l}-0.087 \\
(0.060)\end{array}$ & & \\
\hline Gen X & & $\begin{array}{c}-0.144^{* *} \\
(0.058)\end{array}$ & & \\
\hline Boomers & & $\begin{array}{l}-0.097 \\
(0.059)\end{array}$ & & \\
\hline Discussions without moderation\#Millennial & & $\begin{array}{c}0.037 \\
(0.036)\end{array}$ & & \\
\hline Discussions without moderation\#Gen X & & $\begin{array}{l}0.028 \\
(0.036)\end{array}$ & & \\
\hline Discussions without moderation\#Boomer & & $\begin{array}{l}0.017 \\
(0.036)\end{array}$ & & \\
\hline Discussions with moderation \#Millennial & & $\begin{array}{c}0.039 \\
(0.036)\end{array}$ & & \\
\hline Discussions with moderation \#Gen X & & $\begin{array}{c}0.031 \\
(0.035)\end{array}$ & & \\
\hline Discussions with moderation\#Boomer & & $\begin{array}{l}-0.025 \\
(0.035)\end{array}$ & & \\
\hline Submit questions\#Millennial & & $\begin{array}{c}0.005 \\
(0.041)\end{array}$ & & \\
\hline Submit questions\#Gen $X$ & & $\begin{array}{c}0.034 \\
(0.040)\end{array}$ & & \\
\hline Submit questions\#Boomer & & $\begin{array}{l}-0.045 \\
(0.040)\end{array}$ & & \\
\hline Chat questions\#Millennial & & $\begin{array}{l}0.008 \\
(0.044)\end{array}$ & & \\
\hline Chat questions\#Gen $\mathrm{X}$ & & $\begin{array}{c}0.042 \\
(0.043)\end{array}$ & & \\
\hline Chat questions\#Boomer & & $\begin{array}{l}-0.005 \\
(0.044)\end{array}$ & & \\
\hline Live questions\#Millennial & & $\begin{array}{l}0.038 \\
(0.039)\end{array}$ & & \\
\hline
\end{tabular}




\begin{tabular}{|c|c|c|c|c|}
\hline & ACME & $\begin{array}{l}\text { Interaction with } \\
\text { generation }\end{array}$ & $\begin{array}{l}\text { Interaction with } \\
\text { time online }\end{array}$ & $\begin{array}{l}\text { Interaction with } \\
\text { prior website use }\end{array}$ \\
\hline Live questions\#Gen $\mathrm{X}$ & & $\begin{array}{c}0.027 \\
(0.039)\end{array}$ & & \\
\hline Live questions\#Boomer & & $\begin{array}{c}0.007 \\
(0.040)\end{array}$ & & \\
\hline All information\#Millennial & & $\begin{array}{l}-0.033 \\
(0.037)\end{array}$ & & \\
\hline All information\#Gen X & & $\begin{array}{l}-0.020 \\
(0.035)\end{array}$ & & \\
\hline All information\#Boomer & & $\begin{array}{l}-0.017 \\
(0.036)\end{array}$ & & \\
\hline Overview\#Millennial & & $\begin{array}{l}-0.004 \\
(0.036)\end{array}$ & & \\
\hline Overview\#Gen X & & $\begin{array}{c}0.030 \\
(0.035)\end{array}$ & & \\
\hline Overview\#Boomer & & $\begin{array}{c}0.000 \\
(0.036)\end{array}$ & & \\
\hline Come up with ideas\#Millennial & & $\begin{array}{c}0.060 \\
(0.041)\end{array}$ & & \\
\hline Come up with ideas\#Gen $X$ & & $\begin{array}{c}0.044 \\
(0.040)\end{array}$ & & \\
\hline Come up with ideas\#Boomer & & $\begin{array}{c}0.031 \\
(0.040)\end{array}$ & & \\
\hline Discuss ideas\#Millennial & & $\begin{array}{l}-0.001 \\
(0.040)\end{array}$ & & \\
\hline Discuss ideas\#Gen X & & $\begin{array}{l}0.005 \\
(0.039)\end{array}$ & & \\
\hline Discuss ideas\#Boomer & & $\begin{array}{c}0.039 \\
(0.039)\end{array}$ & & \\
\hline Make decisions\#Millennial & & $\begin{array}{l}-0.016 \\
(0.041)\end{array}$ & & \\
\hline Make decisions\#Gen X & & $\begin{array}{l}-0.013 \\
(0.039)\end{array}$ & & \\
\hline Make decisions\#Boomer & & $\begin{array}{l}-0.034 \\
(0.040)\end{array}$ & & \\
\hline Anonymity possible\#Millennial & & $\begin{array}{c}0.030 \\
(0.033)\end{array}$ & & \\
\hline Anonymity possible\#Gen $X$ & & $\begin{array}{c}0.001 \\
(0.032)\end{array}$ & & \\
\hline Anonymity possible\#Boomer & & $\begin{array}{l}0.023 \\
(0.032)\end{array}$ & & \\
\hline Weak\#Millennial & & $\begin{array}{c}0.040 \\
(0.038)\end{array}$ & & \\
\hline Weak\#Gen X & & $\begin{array}{c}0.103 * * * \\
(0.036)\end{array}$ & & \\
\hline Weak\#Boomer & & $\begin{array}{c}0.086^{* *} \\
(0.038)\end{array}$ & & \\
\hline Strong\#Millennial & & $\begin{array}{c}0.059 \\
(0.040)\end{array}$ & & \\
\hline Strong\#Gen X & & $\begin{array}{c}0.128 * * * \\
(0.040)\end{array}$ & & \\
\hline Strong\#Boomer & & $\begin{aligned} 0.093^{* *} \\
(0.042)\end{aligned}$ & & \\
\hline 2.att_access\#Millennial & & $\begin{array}{c}0.006 \\
(0.029)\end{array}$ & & \\
\hline 2.att_access\#Gen X & & $\begin{array}{c}0.018 \\
(0.029)\end{array}$ & & \\
\hline 2.att_access\#Boomer & & $\begin{array}{c}0.072^{* *} \\
(0.030)\end{array}$ & & \\
\hline Time online (Ref. Low) & & & & \\
\hline Intermediate & & & $\begin{array}{l}-0.061 \\
(0.045)\end{array}$ & \\
\hline High & & & $\begin{array}{l}-0.060 \\
(0.044)\end{array}$ & \\
\hline $\begin{array}{ll}\text { Discussions } & \text { without } \\
\text { moderation\#Intermediate } & \end{array}$ & & & 0.010 & \\
\hline Discussions without moderation\#High & & & $\begin{array}{c}0.029 \\
(0.027)\end{array}$ & \\
\hline Discussion with moderation\#Intermediate & & & 0.003 & \\
\hline
\end{tabular}




\begin{tabular}{|c|c|c|c|c|}
\hline & ACME & $\begin{array}{c}\text { Interaction with } \\
\text { generation }\end{array}$ & $\begin{array}{c}\text { Interaction with } \\
\text { time online }\end{array}$ & $\begin{array}{l}\text { Interaction with } \\
\text { prior website use }\end{array}$ \\
\hline \multirow{3}{*}{ Discussion with moderation \#High } & & & $(0.029)$ & \\
\hline & & & $0.046^{*}$ & \\
\hline & & & $(0.026)$ & \\
\hline \multirow[t]{2}{*}{ Submit questions\#Intermediate } & & & $0.075^{* *}$ & \\
\hline & & & $(0.033)$ & \\
\hline \multirow[t]{2}{*}{ Submit questions\#High } & & & 0.043 & \\
\hline & & & $(0.030)$ & \\
\hline \multirow[t]{2}{*}{ Chat questions\#Intermediate } & & & $0.098 * * *$ & \\
\hline & & & $(0.034)$ & \\
\hline \multirow[t]{2}{*}{ Chat questions\#High } & & & 0.017 & \\
\hline & & & $(0.032)$ & \\
\hline \multirow[t]{2}{*}{ Live questions\#Intermediate } & & & 0.041 & \\
\hline & & & $(0.032)$ & \\
\hline \multirow{2}{*}{ Live questions\#High } & & & 0.009 & \\
\hline & & & $(0.031)$ & \\
\hline \multirow[t]{2}{*}{ All information\#Intermediate } & & & -0.012 & \\
\hline & & & $(0.029)$ & \\
\hline \multirow{2}{*}{ All information\#High } & & & 0.016 & \\
\hline & & & $(0.027)$ & \\
\hline \multirow[t]{2}{*}{ Overview\#Intermediate } & & & $0.055^{*}$ & \\
\hline & & & $(0.030)$ & \\
\hline \multirow[t]{2}{*}{ Overview\#High } & & & 0.027 & \\
\hline & & & $(0.028)$ & \\
\hline \multirow[t]{2}{*}{ Come up with ideas\#Intermediate } & & & 0.044 & \\
\hline & & & $(0.033)$ & \\
\hline \multirow{2}{*}{ Come up with ideas\#High } & & & -0.004 & \\
\hline & & & $(0.030)$ & \\
\hline \multirow{2}{*}{ Discuss ideas\#Intermediate } & & & 0.029 & \\
\hline & & & $(0.033)$ & \\
\hline Discuss ideas\#High & & & 0.001 & \\
\hline & & & $(0.030)$ & \\
\hline Make decisions\#Intermediate & & & 0.044 & \\
\hline & & & $(0.033)$ & \\
\hline Make decisions\#High & & & 0.032 & \\
\hline & & & $(0.031)$ & \\
\hline Anonymity possible\#Intermediate & & & $-0.045^{*}$ & \\
\hline & & & $(0.024)$ & \\
\hline Anonymity possible\#High & & & 0.023 & \\
\hline & & & $(0.024)$ & \\
\hline Weak\#Intermediate & & & 0.004 & \\
\hline & & & $(0.029)$ & \\
\hline Weak\#High & & & -0.006 & \\
\hline & & & $(0.028)$ & \\
\hline Strong\#Intermediate & & & $-0.072 * *$ & \\
\hline & & & $(0.033)$ & \\
\hline Strong\#High & & & $-0.057 *$ & \\
\hline & & & $(0.032)$ & \\
\hline Application\#Intermediate & & & 0.010 & \\
\hline & & & $(0.024)$ & \\
\hline Application\#High & & & 0.012 & \\
\hline & & & $(0.023)$ & \\
\hline Prior website use (Ref Low) & & & & \\
\hline Intermediate & & & & $\begin{array}{l}-0.010 \\
(0.046)\end{array}$ \\
\hline High & & & & 0.011 \\
\hline & & & & $(0.044)$ \\
\hline $\begin{array}{l}\text { Discussions } \\
\text { moderation\# Intermediate }\end{array}$ & & & & -0.007 \\
\hline & & & & $(0.028)$ \\
\hline Discussions without moderation\#High & & & & 0.015 \\
\hline & & & & $(0.027)$ \\
\hline Discussions with moderation\#Intermediate & & & & 0.029 \\
\hline & & & & $(0.028)$ \\
\hline Discussions with moderation\#High & & & & $0.050^{*}$ \\
\hline & & & & $(0.027)$ \\
\hline Submit questions\#Intermediate & & & & $\begin{array}{l}-0.006 \\
(0.033)\end{array}$ \\
\hline Submit questions\#High & & & & $\begin{array}{l}-0.001 \\
(0.031)\end{array}$ \\
\hline
\end{tabular}




\begin{tabular}{|c|c|c|c|c|}
\hline & ACME & $\begin{array}{c}\text { Interaction with } \\
\text { generation }\end{array}$ & $\begin{array}{c}\text { Interaction with } \\
\text { time online }\end{array}$ & $\begin{array}{l}\text { Interaction with } \\
\text { prior website use }\end{array}$ \\
\hline Chat questions\#Intermediate & & & & $\begin{array}{l}0.022 \\
(0.033)\end{array}$ \\
\hline Chat questions\#High & & & & $\begin{array}{c}0.001 \\
(0.032)\end{array}$ \\
\hline Live questions\#Intermediate & & & & $\begin{array}{c}0.048 \\
(0.032)\end{array}$ \\
\hline Live questions\#High & & & & $\begin{array}{l}0.036 \\
(0.031)\end{array}$ \\
\hline All information\#Intermediate & & & & $\begin{array}{l}-0.038 \\
(0.028)\end{array}$ \\
\hline All information\#High & & & & $\begin{array}{l}-0.044 \\
(0.027)\end{array}$ \\
\hline Overview\#Intermediate & & & & $\begin{array}{l}-0.029 \\
(0.029)\end{array}$ \\
\hline Overview\#High & & & & $\begin{array}{c}-0.069 * * \\
(0.028)\end{array}$ \\
\hline Come up with ideas\#Intermediate & & & & $\begin{array}{c}0.040 \\
(0.032)\end{array}$ \\
\hline Come up with ideas\#High & & & & $\begin{array}{c}0.035 \\
(0.031)\end{array}$ \\
\hline Discuss ideas\#Intermediate & & & & $\begin{array}{c}0.031 \\
(0.032)\end{array}$ \\
\hline Discuss ideas\#High & & & & $\begin{array}{l}-0.002 \\
(0.031)\end{array}$ \\
\hline Make decisions\#Intermediate & & & & $\begin{array}{c}0.004 \\
(0.032)\end{array}$ \\
\hline Make decisions\#High & & & & $\begin{array}{l}-0.031 \\
(0.032)\end{array}$ \\
\hline Anonymity possible\#Intermediate & & & & $\begin{array}{l}-0.013 \\
(0.024)\end{array}$ \\
\hline Anonymity possible\#High & & & & $\begin{array}{c}0.003 \\
(0.024)\end{array}$ \\
\hline Weak\#Intermediate & & & & $\begin{array}{l}0.025 \\
(0.029)\end{array}$ \\
\hline Weak\#High & & & & $\begin{array}{c}0.022 \\
(0.028)\end{array}$ \\
\hline Strong\#Intermediate & & & & $\begin{array}{l}-0.009 \\
(0.033)\end{array}$ \\
\hline Strong\#High & & & & $\begin{array}{c}0.035 \\
(0.032)\end{array}$ \\
\hline Application\#Intermediate & & & & $\begin{array}{l}-0.017 \\
(0.024)\end{array}$ \\
\hline Application\#High & & & & $\begin{array}{c}-0.050^{* *} \\
(0.024)\end{array}$ \\
\hline Constant & $\begin{array}{c}0.176^{* * *} \\
(0.018)\end{array}$ & $\begin{array}{c}0.271^{* * *} \\
(0.048)\end{array}$ & $\begin{array}{c}0.213 * * * \\
(0.032)\end{array}$ & $\begin{array}{c}0.176^{* * *} \\
(0.031)\end{array}$ \\
\hline Observations & 12576 & 12576 & 12576 & 12576 \\
\hline
\end{tabular}

Standard errors are in parenthesis $* * * p<0.01, * * p<0.05, * p<0.1$ 